\title{
Relações entre Germinação de Sementes de Espécies de Plantas Daninhas e Uso da Condutividade ElÉtrica ${ }^{1}$
}

\author{
Relationships Between Weed Seed Species Germination and Electrical Conductivity Use \\ VOLL, E. ${ }^{2}$, BRIGHENTI, A.M. ${ }^{3}$, GAZZIERO, D.L.P. ${ }^{4}$ e ADEGAS, F.S. ${ }^{5}$
}

\begin{abstract}
RESUMO - Experimentos foram conduzidos em laboratório com o objetivo de determinar relações entre germinação de sementes de plantas daninhas e condutividade elétrica (CE). Foram usadas sementes de amendoim-bravo (Euphorbia heterophylla), carrapicho-de-carneiro (Acanthospermum hispidum), corda-de-viola (Ipomoea grandifolia), guanxuma (Sida rhombifolia), picão-preto (Bidens pilosa) e trapoeraba (Commelina benghalensis) recentemente colhidas. As sementes foram embebidas em água por períodos de 6 até 48 horas, na temperatura de $20^{\circ} \mathrm{C}$, determinandose a $\mathrm{CE}$ das sementes e os níveis de absorção de água. Depois disso, as sementes foram colocadas para germinar. Os maiores niveis de germinação, para sementes embebidas em água por 24 horas, foram obtidos para picão-preto (88\%), amendoim-bravo (31\%) e guanxuma $(30 \%)$; e os menores, para corda-de-viola $(5 \%)$, carrapicho-de-carneiro $(4 \%)$ e trapoeraba $(3 \%)$. As sementes das plantas daninhas avaliadas tendem a germinar totalmente com periodos de embebição a partir de seis horas, ao passo que a sua absorção tende a aumentar e a CE das sementes, a não acompanhar os níveis de absorção ao final de maiores períodos. O uso da condutividade elétrica merece maiores estudos, uma vez que pode contribuir para uma eficiente e mais rápida avaliação da dinâmica de bancos de sementes de plantas daninhas em lavouras.
\end{abstract}

Palavras-chave: Euphorbia heterophylla, Acanthospermum hispidum, Ipomoea grandifolia, Sida rhombifolia, Bidens pilosa e Commelina benghalensis.

\begin{abstract}
Experiments were carried out under laboratory conditions to determine relationships between weed seed germination and electrical conductivity (EC). Recently-picked seeds of Euphorbia heterophylla, Acanthospermum hispidum, Ipomoea grandifolia, Sida rhombifolia, Bidens pilosa and Commelina benghalensis were used. The seeds were soaked in water for periods of six up to 48 hours, at $20{ }^{\circ} \mathrm{C}$, to determine EC and water absorption levels and placed to germinate. The highest germination levels, for seeds soaked in water for $24 \mathrm{~h}$, were obtained for B. pilosa (88\%), E. heterophylla and S. rhombifolia (30\%) and the lowest levels were obtained for I. grandifolia (5\%), A. hispidum (4\%) and C. benghalensis (3\%). The weeds tested tend to germinate totally with a soaking periods $\geq$ six hours, while water absorption tends to increase with CE tending not to accompany absorption levels at the end of longer periods. Further studies must be conducted on the use of electrical conductivity, what may provide an effective and faster evaluation of the dynamics of weed seed banks under a farming system.
\end{abstract}

Key words: Euphorbia heterophylla, Acanthospermum hispidum, Ipomoea grandifolia, Sida rhombifolia, Bidens pilosa and Commelina benghalensis.

\section{INTRODUÇÃO}

O comportamento de bancos de sementes de plantas daninhas no solo, em lavouras como as de soja, considera o aproveitamento de água no solo para o inicio da germinação, sua intensidade e velocidade de germinação, promovendo antecipação ou atraso em relação à

1 Recebido para publicação em 17.10.2002 e na forma revisada em 11.8.2003.

2 Eng.-Agr., Dr., Pesquisador em Plantas Daninhas da Embrapa Soja, Caixa Postal 231, 86001-970 Londrina-PR, Bolsista do CNPq, <voll@cnpso.embrapa.br>; ${ }^{3}$ Eng.-Agr., Dr., Pesquisador em Plantas Daninhas da Embrapa Soja; ${ }^{4}$ Eng.-Agr., M.S., Pesquisador em Plantas Daninhas da Embrapa Soja. ${ }^{5}$ Eng.-Agr., M.S., Plantas Daninhas, EMATER-PR, Caixa Postal 231, 86001-970 Londrina-PR. 
emergência da cultura. Esse fato é economicamente importante em relação à maior ou menor competição das plantas daninhas que se estabelece com a espécie cultivada.

Vários pesquisadores têm descrito aspectos botânicos, a importância, a distribuição (Kissmann \& Groth, 1992; Lorenzi, 2000a,b), os aspectos de fisiologia (Pedralli, 1983) e o controle de plantas daninhas (Lorenzi, 2000a). A germinação das espécies está associada a fatores genéticos e ambientais que determinam o seu grau de dormência (Chancellor, 1982). Por sua vez, o conhecimento do estado de dormência do banco de sementes no solo é importante para a estimativa de futuros problemas com plantas daninhas em culturas (Taylorson, 1985).

A tensão de água no solo e o período de absorção de água pelas sementes, entre outros fatores, determinam os respectivos níveis e velocidade de emergência (Popinigis, 1977). Taxas de emergência a campo podem decrescer em função da menor temperatura presente em profundidade maior de semeadura, enquanto aumentos de temperatura podem compensar o menor potencial de água no solo (Lindstrom et al., 1976). Aumentos lineares entre períodos de absorção de água e germinação de sementes de capim-marmelada (Brachiaria plantaginea) foram observados (Freitas et al., 1990; Voll et al., 1997). Variações na quantidade de absorção de água, na condutividade elétrica, na porcentagem e velocidade de germinação foram observadas para sementes de capim-marmelada, em função da idade de coleta de diferentes lotes de sementes (Voll et al., 1997). A duração dos períodos de embebição pode levar à germinação máxima de sementes de picão-preto (Bidens pilosa) (Chivinge, 1996) ou reduzir a sua germinação (Reedy \& Singh, 1992). Por sua vez, sementes de corda-de-viola (Ipomoea aristolochiaefolia) só germinavam quando atingiam embebição de $72 \%$ de água do seu peso, permanecendo $60 \%$ como sementes duras e $2 \%$ de sementes embebidas sem germinar (Mikusinski, 1987). Condições de permeabilidade do tegumento das sementes à água, como em capim-colchão (Digitaria sanguinalis), não se relacionaram à sua dormência, uma vez que as sementes dormentes absorveram água tão rapidamente quanto as não-dormentes (Gianfagna \& Pridham, 1951). Sementes que apresentam mucilagens, como as de amendoim-bravo (Euphorbia heterophylla), absorvem água e podem apresentar vantagens na germinação (Harper \& Benton, 1966). Outros fatores que determinam a duração do período da germinação de espécies como amendoim-bravo são a ocorrência de temperaturas alternadas, o estresse hídrico, os potenciais osmóticos, o $\mathrm{pH}$ e a profundidade de semeadura (Bannon et al., 1978).

A qualidade fisiológica das sementes exerce fundamental importância na germinação e na emergência em solo. A condutividade elétrica tem sido proposta como um teste para avaliar o vigor das sementes (Matheus \& Powell, 1981; AOSA, 1983; Marcos Filho et al., 1987), visto que o valor da condutividade é função da quantidade de lixiviados liberados durante a embebição das sementes, estando diretamente relacionada com a integridade das membranas celulares.

O objetivo deste trabalho foi determinar as relações existentes entre fatores de germinação de sementes de plantas daninhas e o uso da condutividade elétrica, envolvendo as espécies de amendoim-bravo, carrapicho-decarneiro, corda-de-viola, guanxuma, picão-preto e trapoeraba.

\section{MATERIAL E MÉTODOS}

O trabalho foi conduzido em laboratório, em abril de 1996, utilizando sementes de amendoim-bravo (Euphorbia heterophylla), carrapicho-de-carneiro (Acanthospermum hispidum), corda-de-viola (Ipomoea grandifolia), guanxuma (Sida rhombifolia), picão-preto (Bidens pilosa) e trapoeraba (Commelina benghalensis) aérea, colhidas no período. As sementes apresentavam 11,$7 ; 11,7 ; 11,3 ; 9,2 ; 12,3 ;$ e $16,1 \%$ de umidade, respectivamente, no início do experimento. Os teores de umidade foram determinados em estufa a $105 \pm 3{ }^{\circ} \mathrm{C}$, durante 24 horas (Brasil, 1992), em 400 sementes. Esses teores de umidade foram incluídos nos cálculos das porcentagens finais de embebição. Após as pesagens iniciais, quatro repetições de 100 sementes foram imersas em água destilada/ deionizada e mantidas em ambiente a $20{ }^{\circ} \mathrm{C}$, em células de condutivímetro, por períodos variáveis de $6,12,18,24$ e 48 horas, não tendo testemunha sem embebição. 
Após cada período de embebição, foi determinada a condutividade elétrica ( $\mathrm{CE} \mu \mathrm{A})$ segundo Krzyzanowski et al. (1991), usando condutivimetro ASA-610, em 4 volts. Foram colocadas cinco sementes por célula para melhorar a precisão das determinações, resultando em 20 células por espécie. Os resultados foram expressos em $\mu \mathrm{A} /$ semente.

Para determinação da porcentagem de absorção de água, as sementes foram retiradas das células do condutivímetro, sendo feitas as pesagens finais das sementes embebidas, que foram colocadas para germinar.

O teste de germinação foi conduzido em caixas plásticas do tipo gerbox, em que as sementes foram distribuídas de modo uniforme sobre quatro folhas de papel-filtro umedecidas com $12 \mathrm{~mL}$ de água e tampadas. As caixas foram colocadas em germinador, sob ciclos de $14 / 10$ horas de $30 / 20^{\circ} \mathrm{C}, 90 \pm 5 \%$ UR e luz fluorescente difusa externa. Foram feitas contagens diárias da porcentagem de sementes germinadas, computando-se aquelas que apresentaram protrusão da radícula de $2,0 \mathrm{~mm}$, até cessar o processo. A determinação do índice de velocidade de germinação das sementes de cada tratamento foi feita conforme Maguire (1962), realizando contagens diárias do número de sementes germinadas.

O experimento foi conduzido em delineamento inteiramente casualizado com quatro repetições. Os dados obtidos foram submetidos à análise da variância, sendo aplicado o teste F de significância a $5 \%$ de probabilidade. Equações de regressão foram estabelecidas entre niveis de absorção de água, condutividade elétrica e germinação de sementes das espécies, em relação aos períodos de embebição das sementes e determinação de graus de associação entre as variáveis determinadas.

\section{RESULTADOS E DISCUSSÃO}

\section{A. Sementes de carrapicho-de-carneiro}

A intensidade de absorção de água das sementes aumentou em relação ao período de 48 horas de embebição $\left(r^{2}=0,99\right)$, ao passo que os níveis de lixiviação eletrolitica mantiveram-se inalterados $\left(\mathrm{r}^{2}=0,23\right)$, assim como a germinação $\left(r^{2}=0,01\right)$ (Figura 1a).
Ocorreu alta correlação entre a germinação e a $\mathrm{CE}\left(\mathrm{r}^{2}=0,84\right)$, que não se alterou de modo significativo após o período de seis horas de embebição. A germinação não se correlacionou com a absorção de água $\left(r^{2}=0,09\right)$. Os níveis de CE também não apresentaram correlação com a intensidade de absorção de água $\left(\mathrm{r}^{2}=\right.$ $0,01)$.

A condutividade elétrica das sementes apresentou valores de $281,8 \mu \mathrm{A}$ (cinco sementes), ou $56,4 \mu \mathrm{A} /$ semente/24 horas de embebição em água.

Considerando-se adequada para executar a condutividade elétrica a embebição em água por 24 horas, a germinação das sementes de carrapicho-de-carneiro foi de $6,9 \%$; o IVG, de 0,81; a absorção de água, de $86,7 \%$; e a CE, de $56,4 \mu \mathrm{A} /$ semente.
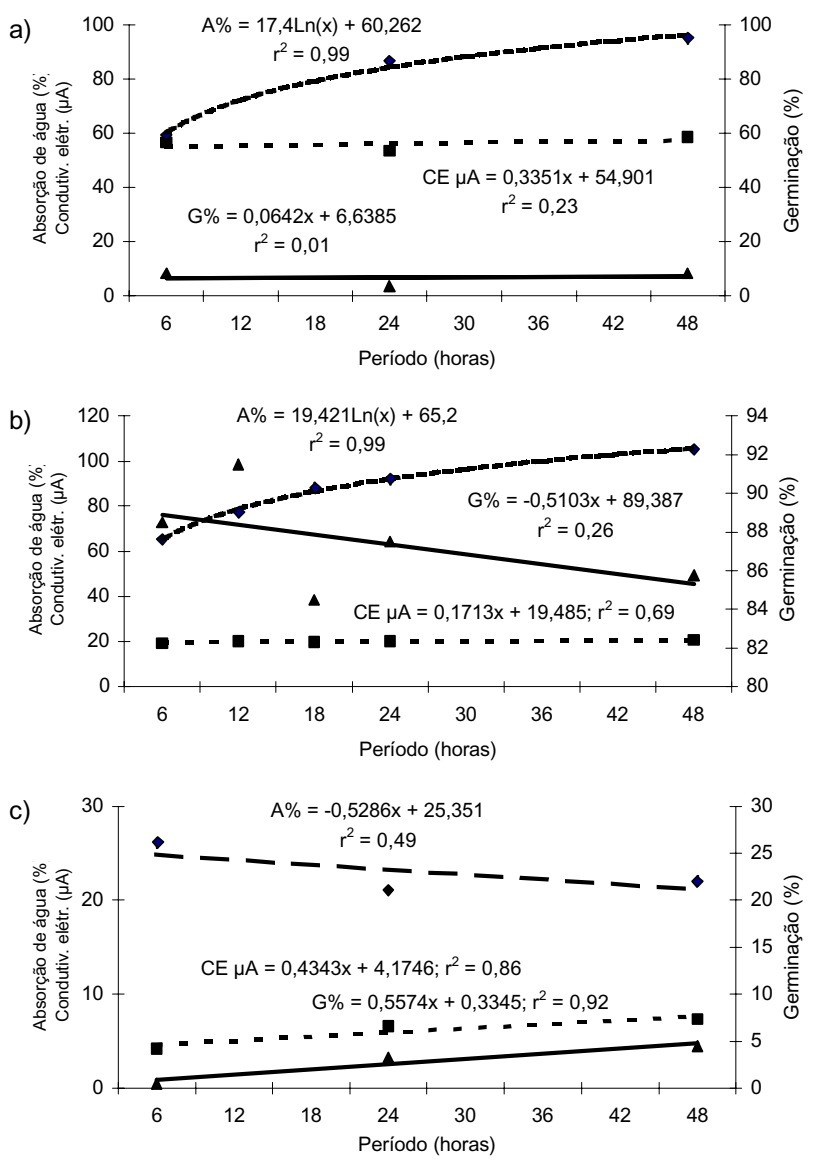

Figura 1 - Níveis de absorção de água (A\%), condutividade elétrica $(\mathrm{CE} \mu \mathrm{A})$ e germinação $(\mathrm{G} \%)$ de sementes de (a) carrapicho-de-carneiro, (b) picão-preto e (c) trapoeraba, em função de períodos de embebição em água.

Planta Daninha, Viçosa-MG, v.21, n.1, p.181-189, 2003 
A germinação encerrou-se aos 12 dias. A taxa de germinação não foi afetada pelos períodos de embebição maiores do que 6 e até 48 horas, embora em relação aos acréscimos de absorção de água eles fossem significativos, variando entre 59,5 e 94,9\%.

Observa-se, portanto, que a germinação do carrapicho-de-carneiro foi relativamente baixa, não progredindo com maiores periodos de embebição. A germinação e a CE das sementes, com relações constantes entre si após seis horas de embebição, não apresentaram associação com o período de embebição, embora a absorção de água tenha aumentado e apresentado alta associação com o período.

\section{B. Sementes de picão-preto}

A intensidade de absorção de água das sementes aumentou até o periodo de 48 horas de embebição $\left(r^{2}=0,99\right)$, enquanto os niveis de lixiviação eletrolítica (CE) não foram significativamente alterados $\left(r^{2}=0,69\right)$, assim como a germinação $\left(r^{2}=0,26\right)$ (Figura $\left.1 b\right)$.

Não ocorreu associação entre a germinação e a $C E\left(r^{2}=0,01\right)$, e as determinações não apresentaram variações significativas após o período de embebição de seis horas. A germinação também não se correlacionou com a absorção de água $\left(\mathrm{r}^{2}=0,35\right)$, uma vez que o nível máximo de germinação já foi atingido no período mínimo de embebição. Os níveis de $\mathrm{CE}$, no entanto, apresentaram associação média com a absorção de água pelas sementes $\left(\mathrm{r}^{2}=\right.$ $0,71)$.

A CE das sementes apresentou valores médios de 100,5 $\mu \mathrm{A}$ (cinco sementes), ou $20,1 \mu \mathrm{A} /$ semente/24 horas de embebição em água.

Considerando-se adequada para executar a condutividade elétrica a embebição em água por 24 horas, a germinação das sementes picãopreto foi de $87,5 \%$; o IVG, de 19,1; a absorção de água, de $91,7 \%$; e a $\mathrm{CE}$, de $20,1 \mu \mathrm{A} /$ semente.

A germinação encerrou-se aos sete dias. Os dados do experimento indicaram que, para os altos niveis de germinação obtidos para o picão (84 a 92\%), o período mínimo de 6 horas de embebição foi suficiente e que a taxa de germinação obtida com períodos crescentes até 48 horas não indicou tendência de redução significativa. Reedy \& Singh (1992) observaram que, com o aumento do período de inundação do solo, a germinação das sementes de picãopreto (B. pilosa) diminuía; a inundação, mesmo por um dia após a semeadura, reduziu a emergência para 25\%, comparada à não-inundação, com $56 \%$ de emergência. Em outro experimento, sementes de picão-preto iniciavam o processo de germinação com menos de 24 horas de embebição, obtendo uma germinação máxima de 59\% num período de embebição de cinco dias (Chivinge, 1996).

Observa-se, portanto, que a germinação do picão-preto foi relativamente alta, maior do que a dos dados comparáveis, e não evoluiu com maiores períodos de embebição. A germinação e a $\mathrm{CE}$ das sementes, com relações de certo modo constantes entre si após seis horas de embebição, não apresentaram associação com o período de embebição, embora a absorção de água tenha aumentado e apresentado alta associação com o período.

\section{Sementes de trapoeraba (aérea)}

A intensidade de absorção de água das sementes tendeu a declinar após o período de embebição de seis horas $\left(\mathrm{r}^{2}=0,49\right)$. Niveis de lixiviação eletrolítica $(\mathrm{CE})$ das sementes não aumentaram significativamente em função do período de embebição das sementes $\left(r^{2}=0,86\right)$, o mesmo acontecendo com a germinação $\left(r^{2}=\right.$ 0,92) (Figura 1c).

Ocorreu alta associação entre a germinação e os níveis de $\operatorname{CE}\left(r^{2}=0,99\right)$, considerando que ambos apresentaram pequenas variações com os períodos de embebição. A germinação correlacionou-se com a absorção de água de modo inverso $\left(\mathrm{r}^{2}=-0,77\right)$. Já os níveis de $\mathrm{CE}$ apresentaram alta correlação negativa com a intensidade de absorção de água $\left(\mathrm{r}^{2}=-0,84\right)$.

A CE das sementes apresentou valores médios de 33,0 $\mu \mathrm{A}$ (cinco sementes), ou 6,6 $\mu \mathrm{A} /$ semente/24 horas de embebição em água.

Considerando-se adequada para executar a condutividade elétrica a embebição em água por 24 horas, a germinação das sementes de trapoeraba foi de $3,2 \%$; o IVG, de 3,1 ; a absorção de água, de $21,1 \%$; e a CE, de $6,6 \mu \mathrm{A} /$ semente. 
Observa-se, portanto, que a germinação da trapoeraba foi relativamente baixa e tendeu a progredir com maiores períodos de embebição, sem aumentar a absorção de água. A germinação encerrou-se aos 12 dias. Supõe-se que variações podem ocorrer nas amostras em função da grande variabilidade no tamanho, na forma e na coloração que as sementes apresentam, além de origem e idade. A germinação e a CE das sementes, com alta associação entre si, não evoluíram significativamente com o período de embebição ou com a absorção de água.

\section{Sementes de amendoim-bravo}

A intensidade de absorção de água das sementes aumentou até o período de 48 horas de embebição $\left(r^{2}=0,99\right)$, bem como os niveis de lixiviação eletrolítica $(\mathrm{CE})\left(\mathrm{r}^{2}=0,99\right)$, enquanto a germinação aumentou até o periodo de 24 horas, decrescendo após, até as 48 horas $\left(r^{2}=0,04\right)$ (Figura 2d).

Não ocorreu associação entre a germinação e os niveis de $\mathrm{CE}\left(\mathrm{r}^{2}=0,06\right)$, pelo fato de a germinação e a $\mathrm{CE}$ só terem evoluído até o período de 24 horas de embebição, tendo sido desfavoráveis à germinação após esse período. A germinação não se correlacionou com a absorção de água $\left(r^{2}=0,14\right)$. Os níveis de $\mathrm{CE}$ apresentaram alta correlação com a intensidade de absorção de água $\left(r^{2}=0,98\right)$.

A CE das sementes apresentou valores de $168,3 \mu \mathrm{A}$ (cinco sementes), ou 33,7 $\mu \mathrm{A} / \mathrm{se}$ mente/24 horas de embebição em água.

Considerando-se adequada para executar a condutividade elétrica a embebição em água por 24 horas, a germinação das sementes de amendoim-bravo foi de $30,5 \%$; o IVG, de 5,2 ; a absorção de água, de 128,0\%; e a CE, de $33,7 \mu \mathrm{A} /$ semente. A taxa de germinação aumentou com o período de embebição de até 24 horas, diminuindo depois. Os acréscimos de absorção de água foram significativos, variando entre 93,4 e 151,9\% no período entre 6 e até 48 horas. O índice de velocidade de germinação decresceu de 24 para 48 horas. A germinação encerrou-se aos 12 dias.

Etejere \& Okoko (1989) observaram que sementes de E. heterophylla tinham 95\% de germinação, praticamente não apresentaram dormência e seu peso aumentou em 63\% após
36 horas de embebição em água. No experimento conduzido observa-se menor taxa de germinação (<30,5\%) e maior teor de absorção de água (> 128\%), o que leva a considerar aspectos fisiológicos diferentes para as sementes testadas em ambos os casos.

A presença de mucilagem nas sementes indica vantagens na germinação de amendoimbravo (Harper \& Benton, 1966), bem como a adaptação a outros fatores ambientais (Bannon et al., 1978). Comumente, em lavouras, são constatadas altas intensidades de emergência, fato não verificado para as demais espécies presentes num banco de sementes, que só germinam mais tarde, sob condições mais favoráveis de umidade.
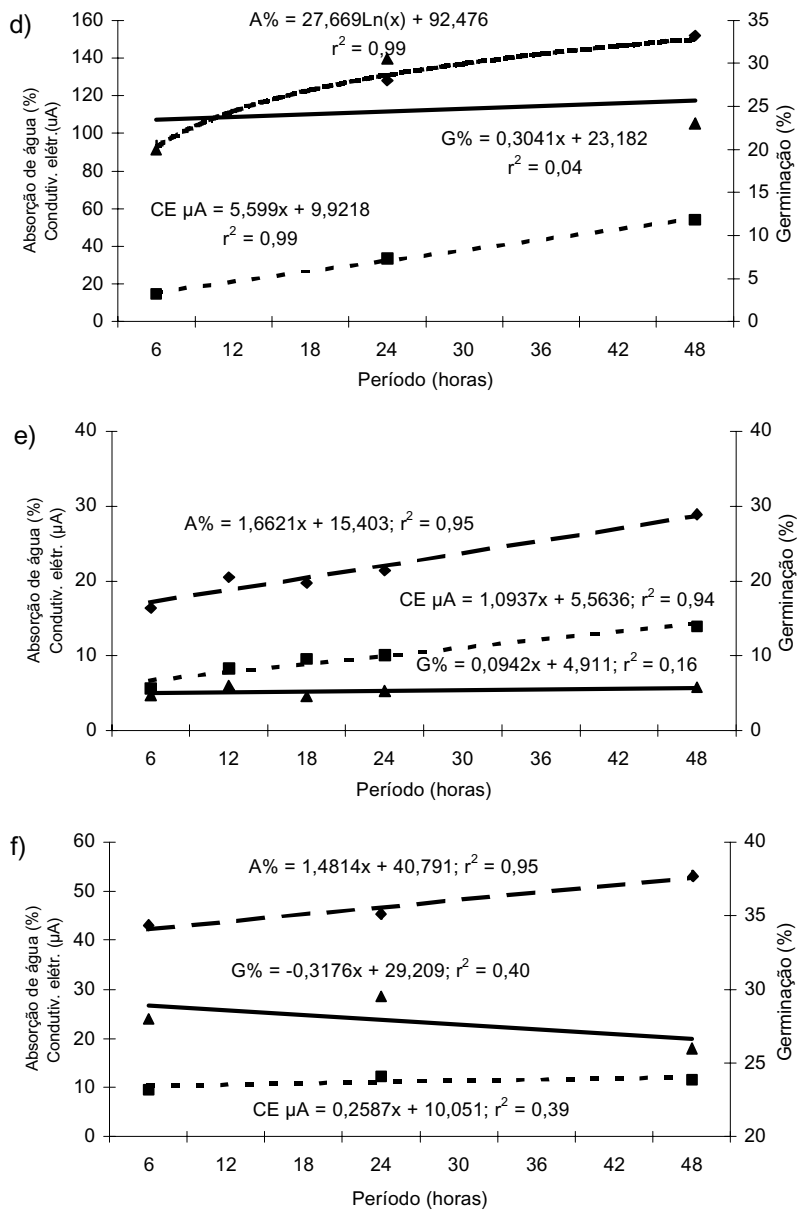

Figura 2 - Níveis de absorção de água (A\%), condutividade elétrica $(\mathrm{CE} \mu \mathrm{A})$ e germinação $(\mathrm{G} \%)$ de sementes de (d) amendoim-bravo, (e) corda-de-viola e (f) guanxuma, em função de períodos de embebição em água.

Planta Daninha, Viçosa-MG, v.21, n.1, p.181-189, 2003 
Observa-se, portanto, que a germinação do amendoim-bravo foi relativamente média e não progrediu com períodos de embebição maiores do que seis horas, podendo apresentar taxas de germinação mais elevadas. A germinação não apresentou associação significativa com a embebição, ao passo que a $\mathrm{CE}$ das sementes mostrou-se associada aos períodos de embebição e à absorção de água.

\section{E. Sementes de corda-de-viola}

A intensidade de absorção de água das sementes aumentou até o período de 48 horas de embebição $\left(r^{2}=0,95\right)$, bem como os niveis de lixiviação eletrolítica (CE) $\left(r^{2}=0,94\right)$, enquanto a germinação não evoluiu no periodo $\left(\mathrm{r}^{2}=\right.$ $0,16)$ (Figura 2e).

Não ocorreu associação entre a germinação e a $\mathrm{CE}\left(\mathrm{r}^{2}=0,18\right)$, uma vez que ocorreu a evolução da CE e não da germinação no período de embebição. A germinação também não se correlacionou com a absorção de água $\left(\mathrm{r}^{2}=0,16\right)$. Os niveis de CE apresentaram alta correlação com a intensidade de absorção de água $\left(\mathrm{r}^{2}=\right.$ $0,93)$.

A CE das sementes apresentou valores de $50,6 \mu \mathrm{A}$ (cinco sementes), ou 10,1 $\mu \mathrm{A} /$ semente/ 24 horas de embebição em água.

Considerando-se adequada para executar a condutividade elétrica a embebição em água por 24 horas, a germinação das sementes de corda-de-viola foi de 5,2\%; o IVG, de 2,4; a absorção de água, de $21,4 \%$; e a $\mathrm{CE}$, de $10,1 \mu \mathrm{A} /$ semente. A taxa de germinação permaneceu constante nos períodos de embebição entre 6 e 48 horas, embora os acréscimos de absorção de água fossem significativos, variando entre 16,4 e $28,9 \%$. A germinação encerrou-se aos 14 dias.

Os resultados diferem daqueles obtidos para a mesma espécie por Mikusinski (1987), em que ocorreu germinação máxima de 38\%, com absorção de $72 \%$ de água em 24 horas de embebição e progressão linear do teor de água das sementes até as 48 horas de embebição, ou seja, comparado a uma germinação de 5,2\% (máxima de 5,8\%) e absorção de água de 21,4\% . Variações na produção de "sementes duras" são influenciadas pelo ano de produção das sementes (Stoller \& Wax, 1973). As condições de temperatura a que a planta-mãe foi submetida durante o desenvolvimento das sementes podem exercer considerável influência nas respostas quantitativas de germinação na presença da luz (Probert et al., 1985).

Constata-se, portanto, que a germinação da corda-de-viola foi relativamente baixa, tendo apresentado menor taxa de germinação e absorvido menos água em relação a outras sementes coletadas da mesma espécie, sem progredir com maiores períodos de embebição. A germinação e a CE das sementes não apresentaram associação entre si, considerandose que ambas apresentam dados com pequenas variações, embora a absorção de água e a $\mathrm{CE}$ tenham aumentado e apresentado alta associação com o período de embebição.

\section{F. Sementes de guanxuma}

A intensidade de absorção de água das sementes aumentou até o período de 48 horas de embebição $\left(r^{2}=0,95\right)$, porém não com os níveis de lixiviação eletrolítica $(\mathrm{CE})\left(\mathrm{r}^{2}=0,39\right)$, enquanto a germinação se manteve até o período de 24 horas, tendendo a decrescer após, até as 48 horas (Figura 2f).

Não ocorreu associação entre a germinação e a $\mathrm{CE}\left(\mathrm{r}^{2}=0,04\right)$, não tendo ocorrido evolução dos dados após seis horas de embebição. A germinação apresentou correlação média com a absorção de água $\left(r^{2}=0,63\right)$, e os aumentos de absorção resultaram em tendência de redução da germinação ao final de 48 horas de embebição. Os niveis de $\mathrm{CE}$ não apresentaram correlação com a intensidade de absorção de água $\left(\mathrm{r}^{2}=0,19\right)$.

A CE das sementes apresentou valores de $61,9 \mu \mathrm{A}$ (cinco sementes), ou $12,4 \mu \mathrm{A} /$ semente/ 24 horas de embebição em água.

Considerando-se adequada para executar a condutividade elétrica a embebição em água por 24 horas, a germinação das sementes de guanxuma foi de $29,5 \%$; o IVG, de 9,9; a absorção de água, de 45,3\%; e a CE, de 12,4 $\mu \mathrm{A} /$ semente. Pequenas alterações na taxa de germinação evoluíram com os períodos de embebição até 24 horas e decresceram até 48 horas, embora os acréscimos de absorção de água fossem constantes, variando entre 43,1 e $53,2 \%$. A germinação encerrou-se aos 16 dias. 
Observa-se, portanto, que a germinação da guanxuma foi relativamente média e não progrediu com maiores períodos de embebição. A germinação e a $\mathrm{CE}$ das sementes, com relações constantes entre si após seis horas de embebição, não apresentaram associação com o período de embebição, embora a absorção de água tenha aumentado e apresentado alta associação com esse período.

\section{Comparações entre espécies}

As porcentagens de absorção de água para as diferentes espécies daninhas, no periodo de 24 horas, em ordem crescente, foram: cordade-viola $(21,0)<$ trapoeraba $(21,1)<$ guanxuma $(45,3)<$ picão-preto $(85,7)<$ carrapicho-decarneiro $(86,7)<$ amendoim-bravo $(128,0)$. Aumentos nos teores de absorção de água das sementes de carrapicho-de-carneiro foram significativamente associados aos períodos de embebição de até 48 horas, mas não foram significativos para trapoeraba e corda-de-viola, tendendo a ser desfavoráveis, após o período de 24 horas, para a germinação das espécies amendoim-bravo, guanxuma e picão-preto, que apresentaram as maiores taxas de germinação. O comportamento negativo dessas espécies com maiores períodos de embebição pode ocorrer segundo observações feitas para sementes de picão-preto (Reedy \& Singh, 1992; Chivinge, 1996).

Os niveis de $\mathrm{CE} \mu \mathrm{A} /$ semente, em 24 horas, foram: trapoeraba $(6,6)<$ corda-de-viola $(10,1)$ < guanxuma $(12,4)<$ picão-preto $(20,1)<$ amendoim-bravo $(33,7)<$ carrapicho-de-carneiro $(56,4)$. A quantidade de exsudatos lixiviados das sementes, na água de embebição, pode ser influenciada pelo estádio de desenvolvimento no momento da colheita, pelo grau de deterioração e pela incidência de danos causados pela velocidade de embebição (Powell, 1986), por injúrias no tegumento da semente (Loeffler, 1981), temperatura e tempo de embebição (Loeffler et al., 1988). Os valores de CE estão associados ao estado fisiológico das sementes e aos niveis de germinação de cada espécie.

As porcentagens de germinação em 24 horas de embebição foram: trapoeraba $(3,2)$ $<$ carrapicho-de-carneiro $(3,8)<$ corda-de-viola $(5,2)<$ guanxuma $(29,5)<$ amendoim-bravo $(30,5)<$ picão-preto $(87,5)$. Considerando que essas plantas daninhas são todas espécies anuais de verão, tem-se observado que, principalmente, sementes de amendoim-bravo e de picão-preto germinam em lavouras o ano inteiro e surgem de modo muito rápido, aproveitando condições favoráveis de temperatura e umidade no solo, em períodos muito curtos, em função da sua alta taxa de germinação ou da pouca e rápida superação da dormência.

Os índices de velocidade de germinação (IVG) foram: carrapicho-de-carneiro $(0,6)<$ corda-de-viola $(2,4)<$ trapoeraba $(3,2)<$ amendoim-bravo $(5,2)<$ guanxuma $(9,9)<$ picão-preto $(19,2)$. Observou-se que o índice está relacionado com a intensidade de germinação e que pode apresentar variações em função do periodo de embebição.

Nas comparações de comportamento das espécies amendoim-bravo e corda-de-viola, em relação às literaturas citadas, observa-se que pode ocorrer alta germinação e menor necessidade de água para amendoim-bravo, e, para corda-de-viola, maior germinação com maior absorção de água. Voll et al. (1997) observaram que em lote mais velho de capim-marmelada (B. plantaginea), com menor dormência e maior germinação, ocorreu maior porcentagem de absorção de água, CE, IVG e germinação.

Em campo, fatores de manejo, como coberturas vegetais, podem determinar o início da germinação e reduzir a germinação e a emergência de espécies de plantas daninhas devido aos fatores água, luz, temperatura ou alelopatia (Osman et al., 1991). O posicionamento das sementes na superfície do solo e seu ressecamento também podem contribuir para uma menor germinação (Machado-Neto \& Pitelli, 1988). Padrões de emergência de algumas espécies podem ser aumentados pelo cultivo (Zimbdahl et al., 1988), enquanto a germinação e sua periodicidade relacionam-se primeiramente com a ocorrência de chuvas no periodo de aumento das temperaturas (Stoller \& Wax, 1973).

Em função dos resultados de germinação das sementes, observa-se que as determinações de condutividade elétrica, resultante da medição da sua lixiviação eletrolítica num periodo máximo de até 24 horas de embebição, poderiam ser usadas para indicar e comparar a capacidade de germinação de sementes nas 
distintas espécies de plantas daninhas. Períodos de embebição maiores do que 24 horas podem levar à germinação máxima ou à sua redução, devido à redução dos níveis de oxigênio no metabolismo da semente. As sementes das espécies testadas tendem a germinar totalmente com periodos mínimos de seis horas de embebição em água, ao passo que a sua absorção tende a aumentar e a CE das sementes, a não acompanhar os níveis de absorção ao final de maiores períodos.

O uso da condutividade elétrica poderia contribuir para melhor avaliação anual de bancos de sementes no solo, resultantes de infestações em lavouras, num período mínimo de tempo em relação a um semelhante teste de germinação em germinador.

\section{AGRADECIMENTOS}

Às pessoas que colaboraram na publicação deste trabalho e ao Conselho Nacional de Desenvolvimento Científico e Tecnológico (CNPq), pela concessão de bolsa de pesquisa.

\section{LITERATURA CITADA}

ASSOCIATION OF OFFICIAL SEED ANALYSTS AOSA. Seeds vigor testing handbook. Lansing, 1983. 93 p. (Contribution, 32).

BANNON, J. S.; BARKER, J. B.; ROGERS, R. L. Germination of wild poinsettia (Euphorbia heterophylla). Weed Sci., v. 26, n. 3, p. 221-225, 1978.

BRASIL. Ministério da Agricultura e Reforma Agrária. Regras para análise de sementes. Brasília: SNAD/DNDV/ CLAV, 1992. $365 \mathrm{p}$.

CHANCELLOR, R. J. Weed seed investigations. In: THOMPSON, J. R. Advances in research and technology of seeds. Wageningen: ISTA, 1982. pt.7, p. 9-29.

CHIVINGE, O. A. Studies on the germination and seedling emergence of Bidens pilosa and its response to fertilizer application. Trans. Zimbabwe Sci. Assoc., v. 70, p. 1-5, 1996.

ETEJERE, E. O.; OKOKO, T. A. Seed production, germination and emergence of Euphorbia heterophylla $\mathrm{L}$. Nigerian J. Bot., v. 2, p. 143-147, 1989.

FREITAS, R. R.; CARVALHO, D. A.; ALVARENGA, A. A. Quebra de dormência e germinação de sementes de capimmarmelada (Brachiaria plantaginea). R. Bras. Fisiol. Veg., v. 2, n. 2, p. 31-35, 1990.

Planta Daninha, Viçosa-MG, v.21, n.1, p.181-189, 2003
GIANFAGNA, F. J.; PRIDHAM, A. M. S. Some aspects of dormancy and germination of crabgrass. Proc. Am. Soc. Hortic. Sci., v. 58, p. 291-297, 1951.

HARPER, J. L.; BENTON, R. A. The germination of seeds on the surface of a water supplying substrate. J. Ecol., v. 54, p. 151-166, 1966.

KISSMANN, K. G.; GROTH, D. Plantas infestantes e nocivas. São Paulo: BASF Brasileira, 1992. t. 2, 798 p.

KRZYZANOWSKI, F. C.; FRANÇA NETO, J. B.; HENNING, A. A. Relato dos testes de vigor disponíveis para as grandes culturas. Inf. ABRATES, v. 1, n. 2, p. 15$50,1991$.

LINDSTROM, M. J.; PAPENDICK, R. J.; KOELLER, F. E. A model to predict winter wheat emergence as affected by soil temperature, water potential, and depth of planting. Agron. J., v. 68, n. 1, p. 137-141, 1976.

LOEFFLER, T. M. The bulk conductivity test as an indicator of soybean seed quality. 1981. $181 \mathrm{f}$.

Dissertation (M.S.) - University of Kentucky, 1981.

LOEFFLER, T. M.; TEKRONY, D. M.; EGLI, D. B. The bulk conductivity test as an indicator of soybean seed quality. J. Seed Technol., v. 12, n. 1, p. 37-53, 1988.

LORENZI, H. Manual de identificação e controle de plantas daninhas: plantio direto e convencional. 5.ed. Nova Odessa: Instituto Plantarum, 2000a. 339 p.

LORENZI, H. Plantas daninhas do Brasil: terrestre, aquáticas, parasitas e tóxicas. 3.ed. Nova Odessa: Instituto Plantarum, 2000b. 608 p.

MACHADO-NETO, J. G.; PITELli, R. A. Profundidade de semeadura na emergência de amendoim-bravo. Pesq. Agropec. Bras., v. 23, n. 11, p. 1203-1208, 1988.

MAGUIRE, J. D. Speed of germination-aid in selection and evaluation for seedling emergence and vigor. Crop Sci., v. 2, n. 1, p. 176-177, 1962.

MARCOS FILHO, J.; CÍCERO, S. M.; SILVA, W. R. Avaliação da qualidade das sementes. Piracicaba: FEALQ, 1987. 230 p.

MATHEUS, S.; POWELL, A. A. Electrical conductivity test. In: Perry, D. A. (Ed.) Handbook of vigour test methods. Zürich: ISTA, 1981. p. 37-42.

MIKUSINSKI, O. M. Teste de embebição e germinação em sementes de Ipomoea aristolochiaefolia. R. Bras.

Sementes, v. 9, n. 3, p. 103-108, 1987. 
OSMAN, M. A.; RAJU, P. S.; REACOCK, J. M. The effect of soil temperature, moisture and nitrogen on Striga solisyurs Kuntze seed germination, viability and emergence on sorghum (Sorghum bicolor) roots under field conditions. Plant Soils, v. 131, n. 2, p. 265-273, 1991.

PEDRALLI, G. Observação sobre a biologia do leiteiro (Euphorbia heterophylla L.) no Estado do Rio Grande do Sul, Brasil. Pelotas: EMBRAPA UEPAE, 1983. 7 p. (Comunicado Técnico)

POPINIGIS, F. Fisiologia da semente. Brasília: AGIPLAN, 1977. 289 p.

POWELL, A. A. Cell membranes and seed leachate conductivity in relation to the quality of seed for sowing. Seed Technol., v. 10, n. 2, p. 81-100, 1986.

PROBERT, R. J.; SMITHM, R. D.; BIRCH, P. Germination responses to light and alternating temperatures in European populations of Dactylis glomerata L. I. Variability in relation to origin. New Phytol., v. 99, p. 305-316, 1985.
REEDY, K. N.; SINGH, M. Germination and emergence of hairy beggarticks (Bidens pilosa). Weed Sci., v. 40, n. 2, p. 195-199, 1992.

STOLLER, G. W.; WAX, L. M. Periodicity of germination and emergence of some annual weeds. Weed Sci., v. 21, n. 6 , p. 574-580, 1973.

TAYLORSON, R. B. The role of seed dormancy and germination in devising weed control methods. In: WORLD SOYBEAN RESEARCH CONFERENCE, 3., 1984, Ames. Proceedings... London: Westwiew Press, 1985. p. 10971104.

VOLL, E. et al. Embebição e germinação de sementes de capim-marmelada (Brachiaria plantaginea (Link) Hitchc.). R. Bras. Sementes, v. 19, n. 1, p. 58-61, 1997.

ZIMBDAHL, R. L. et al. Patterns of weed emergence in tropical soil. Weed Sci., v. 5, p. 603- 608, 1988. 